\title{
LA IMPORTANCIA DE LA COMUNICACIÓN NO VERBAL EN LA CONFIGURACIÓN DE LA IMAGEN CORPORATIVA
}

\author{
Dr. Carlos Fanjul Peyró \\ Profesor de Imagen Corporativa. Universidad San Jorge - Zaragoza
}

\section{Resumen}

La creación de una imagen corporativa sólida, fuerte y positiva supone un trabajo de enriquecimiento constante de los valores y principios de base que definen la realidad de una organización, a los cuales debe ser fiel en todas sus manifestaciones comunicativas. Los componentes no verbales que rodean o configuran cualquiera de estas manifestaciones, emergen como piezas clave en la construcción de imagen, dado el peso pragmático de los mismos dentro del proceso sistémico que implica la formación del principal intangible corporativo.

\section{Palabras clave}

Comunicación no verbal; Escuela de Palo Alto; Imagen corporativa

\section{Abstract}

The creation of a solid, strong and positive corporate image involves a work of constant enrichment of the values and basic principles that define the reality of an organization, whom must remain faithful in all its communicative manifestations. Nonverbal components that surround or form any of these manifestations, emerge as key elements in the image construction, due to their pragmatic influence inside the systemic process that involves the creation of the principal intangible corporative. 


\section{Key words}

Nonverbal Communication; Palo Alto Institute; Corporate image

\section{Introducción}

En la coyuntura social actual, el dicho "una imagen vale más que mil palabras” está progresivamente adquiriendo más relevancia en el mundo de las organizaciones. La diferenciación, la fuerza, la capacidad competitiva y la rentabilidad de las mismas, son conferidas, más que por sus políticas funcionales, por los elementos que componen sus políticas formales. Los intangibles estratégicos y la concepción de la comunicación como herramienta básica de gestión en la construcción y elaboración de estos intangibles, se han configurado como la quintaesencia de la realidad corporativa. La comunicación ha dejado de ser "la guinda” del pastel para convertirse en uno más de los ingredientes básicos, de tal manera que sin ella será imposible que haya empresa (organización o institución), y de su presencia y utilización dependerá no ya el éxito o el fracaso de la empresa, sino su propia existencia. (Ramírez, 1995; Álvarez y Caballero, 2004)

La comunicación en el campo organizacional es un todo, una unidad asentada en la cultura, la identidad y la personalidad corporativa que configurarán su imagen global. Ninguna de estas cuestiones se puede aislar comunicativamente hablando; si falla una parte o se desarrolla de manera inadecuada, las otras se resienten y, de hecho, la comunicación y la imagen de esa organización, correrá graves peligros. La consideración de la comunicación como una entidad sistémica global, supone la concepción cultural de la misma como valor central en la definición y construcción de la personalidad, identidad e imagen de toda organización y que constituirá su principal activo a la hora de permanecer, desarrollarse, crecer y diferenciarse dentro de su mercado y dentro de la sociedad.

Con este planteamiento, es conveniente reflexionar y destacar el rol que los componentes no verbales juegan en el proceso comunicativo y, aplicándolos a la organización, en la configuración de la imagen corporativa de la misma. Teniendo en cuenta que la comunicación no verbal aporta el mayor peso en la construcción del sentido social de la comunicación, su álisis de la imagen corporativa se perfila como “fundamental” para la eficacia y coherencia de la misma. 


\section{Objetivos}

El presente artículo tiene como objetivo principal reflexionar y tomar consciencia de la necesidad y utilidad que supondría asociar y aplicar los conocimientos y los avances en la investigación sobre comunicación no verbal, al campo de la comunicación organizacional y a la creación de imagen corporativa.

\section{Metodología}

El método elegido para abordar este trabajo ha sido la revisión bibliográfica en combinación con técnicas cualitativas (observación) y empíricas. Se pretende con ello ofrecer una visión amplia, fundamentada y razonada de las áreas de conocimiento abordadas y su aplicación a la cuestión de la imagen corporativa.

\section{Un reto para la investigación: los componentes no verbales en la comunicación}

Es obligatorio citar como referente en el estudio de los componentes no verbales de la comunicación a la conocida como Escuela de Palo Alto. Palo Alto es una pequeña ciudad situada al sur de San Francisco. En ella, D. Jackson fundó, en 1959, el Mental Research Institute. Fue el estudio de la esquizofrenia y las patologías en la comunicación lo que permitió establecer una teoría de la comunicación interpersonal que tuvo gran influencia y predicación en los años 70. En Palo Alto también residirá Bateson que formó equipo de investigación con Haley, Weakland y Fry. Bateson ocupa un lugar privilegiado en la historia de la escuela. Su interés por la comunicación se explica por su dedicación a la antropología, la psiquiatría, la evolución biológica y la cibernética, campos de estudio de los que es común denominador. Investigará sobre la comunicación entre animales, la comunicación y las enfermedades mentales y la comunicación humana.

La denominación de "escuela de Palo Alto" o "Universidad Invisible” se produce porque sus miembros (Birdwhistell, Bateson, Mead, Scheflen y Goffman entre otros) están dispersos en el espacio y en el tiempo, teniendo como principal “lugar físico de encuentro” el Instituto de Palo Alto. 
En 1960, Watzlawick entra a formar parte de la escuela. Este autor popularizará más tarde los trabajos de Bateson y escribirá, junto con Beavin y Jackson, el texto que resume los axiomas de su teoría sobre la comunicación humana. ${ }^{1}$

Los miembros de la Universidad Invisible se preocupan, más que por el contenido o la forma de la comunicación, por el contexto y por los efectos: la pragmática de la comunicación humana. Podemos hablar de una "escuela pragmática” de la comunicación cuyo interés va más allá de la sintáctica o la semiótica (Baylon y Mignot, 1996). Estamos ante un grupo de antropólogos, psicólogos, sociólogos y psiquiatras ajenos a los centros de investigación en comunicación que van adquiriendo madurez en los Estados Unidos. La escuela procesal ha triunfado en los centros universitarios de ciencias de la comunicación. La escuela de Palo Alto, por el contrario, tiene cierta dificultad para lograr eco en esos espacios: "Hay que esperar a la crisis de los modelos macrosociológicos para ver reconocida, en los años ochenta, la contribución decisiva de la escuela de Palo Alto a una teoría sobre los procesos de comunicación como interacciones” (Mattelart y Mattelart, 1997: 49).

Los autores de Palo Alto sugieren un modelo polifónico e interactivo de la comunicación, ya que ésta puede entenderse como circuitos de retroalimentación en los que la conducta de cada persona afecta a la de cada una de las otras y es, a su vez, afectada por éstas (Watzlawick y otros, 2002). El estudio de esa interacción polifónica, la comunicación humana, puede subdividirse en tres áreas interdependientes: sintáctica, semántica y pragmática. La sintáctica se ocuparía de los problemas de transmisión de la información (codificación, canales, capacidad, ruido, redundancia y otras propiedades estadísticas del lenguaje); la semántica del significado y la pragmática de cómo la comunicación afecta a la conducta, es decir, de los efectos de la comunicación (Morris, 1958).

Esta escuela se ocupa primordialmente de la pragmática. No se trata del efecto de una comunicación sobre el receptor. Estamos ante un paradigma sistémico, un sistema abierto caracterizado por la totalidad, la retroalimentación y la equifinalidad (Martín Serrano, 1982). Esta perspectiva da lugar a una nueva concepción de la comunicación, la cual dejaría de ser una simple relación entre dos personas: “Este modelo de comunicación no se funda en la imagen del telégrafo o

\footnotetext{
${ }^{1}$ Cfr. WATZLAWICK, P., BEAVIN, J. y JACKSON, D. (2002), Teoría de la Comunicación Humana. Barcelona: Herder.
} 
del ping-pong (un emisor envía un mensaje a un receptor que, a su vez, se convierte en emisor, etc.), sino en la metáfora de la orquesta.” (Bateson y otros, 1994: 5-6)

Frente a los modelos lineales y circulares de la escuela procesal, los autores de la escuela invisible proponen un "modelo orquestal" estableciendo una analogía entre comunicación y una orquesta, entre la forma de la composición musical y la estructura de la comunicación. Scheflen afirma que "la diferencia entre estas dos estructuras es que la composición musical posee una partitura explícita, escrita y conscientemente aprendida y repetida. La partitura de la comunicación no ha sido formulada por escrito y, en cierta medida, ha sido aprendida conscientemente.” (Scheflen, 1973:181)² De la definición de orquesta nos resulta útil la noción de “conjunto”: tocan unidos. Pero también, hablar de partitura es reconocer la existencia de unas leyes, las leyes de la armonía, de la composición musical. Quizá se pueda extender la analogía, pues, a las reglas, patrones, programas y cálculos que gobiernan la pragmática de la comunicación.

En este modelo, la comunicación se concibe como un sistema cultural en el que se inserta el individuo. Un sistema regido por una causalidad que ya no es lineal sino circular, donde el efecto retroactúa sobre la causa, como en una “orquesta” de la que forma parte cada miembro y en la que todo el mundo sigue una "partitura invisible".

La comunicación se concibe como un sistema de canales múltiples en el que el autor social participa en todo momento, tanto si lo desea como si no: por sus gestos, su mirada, su silencio e incluso su ausencia... En su calidad de miembro de una cierta cultura, forma parte de la comunicación, como el músico forma parte de la orquesta. (Bateson y otros, 1994: 6)

¿Qué sentido cabe otorgar a un modelo orquestal? En primer lugar, supera la barrera de la bidireccionalidad, el binomio emisor-receptor. En segundo lugar, permite incorporar la noción de simultaneidad, imposible en un modelo mensaje-respuesta de naturaleza consecutiva; tal es la importancia de la comunicación no verbal en esta escuela. Aquellos modelos que dan prioridad al mensaje lingüístico pueden representarse lineal o bidireccionalmente (Shannon, Gerbner, Schramm...). Pero la comunicación humana no sólo es bidireccional, sino simultánea. Una orquesta en la que múltiples mensajes son ejecutados a la vez, en una línea armónica de varias voces

\footnotetext{
${ }^{2}$ Cita y referencia tomada de BATESON, G. [et. al.] (1994), La nueva comunicación. Barcelona: Cairos, p. 24.
} 
(mensajes verbales y no verbales) que puede interpretar un solo instrumento y en la que, además, todos participan a la vez.

La cuestión que se plantea entonces estriba en cómo leer, cómo puntuar, una larga cadena de retroalimentación. Toda persona cuenta con un repertorio muy extenso de conductas. Sin embargo, de hecho, ciertos comportamientos son mucho más frecuentes que otros, son predecibles, son redundantes. La redundancia, en la comunicación humana, define las reglas de la relación en una interacción. Observar las conductas repetidas, como en el juego del ajedrez, permite averiguar la lógica del sistema, establecer jugadas y tácticas. El punto de partida no es la naturaleza psicológica de los individuos, sino la de los sistemas en los que se insertan. Ante la imposibilidad de estudiar el contenido de la mente, los autores de Palo Alto apuestan por el estudio de lo que es observable, las entradas y salidas, los flujos de retroalimentación del sistema, los comportamientos verbales y no verbales de sus pacientes. El análisis del comportamiento permite establecer cuál es el patrón general de la interacción, un patrón conformado por las reglas que surgen de la repetición o redundancia de los hechos.

Dentro de esta “escuela invisible” se perfilan, de manera informal o tentativa, unos principios que definen las propiedades de la comunicación. Los cinco axiomas metacomunicacionales de la Escuela Pragmática son considerados por Valbuena (1997) principios gnoseológicos de la comunicación, aplicables tanto a la comunicación interpersonal como a la colectiva. En 1967, Watzlawick, Beavin y Jackson publican Teoría de la Comunicación Humana en donde exponen y desarrollan estos principios. Al revisar los axiomas de la escuela se reconocen las influencias de los estudios de Bateson tanto en los conceptos de codificación digital y analógica como en la puntuación de las secuencias de una interacción. Pero Watzlawick, Beavin y Jackson tienen el mérito de sintetizar, organizar y sistematizar, a la vez que explicar con claridad, los hallazgos de su mentor.

\subsection{Un axioma controvertido: es imposible no comunicar}

El axioma más conocido y controvertido es aquel que dice “...no hay no-conducta, o, para expresarlo de modo aún más simple, es imposible no comportarse.” (Watzlawick, Beavin y Jackson, 2002: 50). Palabra, silencio, actividad o inactividad, todo tiene valor de mensaje, por tanto, es imposible no comunicar. 
Retomando el origen etimológico del término “comunicar” (poner en común), podríamos decir que comunicar, aquí, es “ponerse en común”, mostrarse a otros. Pero no todo el mundo está dispuesto a aceptar tan fácilmente este planteamiento, que niega el carácter int equiparando información y comunicación. El profesor Karl E. Rosengren escribe que cuando un individuo no es consciente de sus actos o comportamientos y éstos no son intencionales, estamos ante un comportamiento totalmente no-comunicativo que puede, sin embargo, ofrecer información valiosa al medio que rodea al individuo. (Rosengren, 2000)

Este principio comunicativo “es imposible no comunicar” se verá distorsionado en la comunicación patológica: el enfermo intentará negar la comunicación, huir del compromiso inherente a la comunicación. Ante la presencia de otros, es posible aceptar o bien negar la comunicación. Pero esto último supone siempre una comunicación, hasta en el silencio que evidencia el rechazo de la comunicación. Las descalificaciones (autocontradicciones, incongruencias, cambio de tema, interpretaciones metafóricas o literales siempre fuera de lugar) y los síntomas (fingir somnolencia, ignorancia del idioma o cualquier otra deficiencia que le impida a uno comunicarse) permiten igualmente evadir el compromiso, cuando una persona está obligada a comunicarse pero no quiere o no puede hacerlo.

Pues bien, nos comunicamos, pero también nos comunicamos acerca de la relación, y con el mismo lenguaje. El metalenguaje comunicativo emplea el lenguaje natural. El primer nivel es referencial y equivale al tipo de comunicación que se estudia, por ejemplo, en la escuela procesal. Birdwhistell señala que "si es válida la investigación hecha en Palo Alto por Bateson, Brosin, Fromm-Reichmann, Hockett y McQuown, y en el Instituto Psiquiátrico de Eastern Pennsylvania por Austin, Scheflen y el autor de estas líneas, la transmisión de información no es más importante que lo que denominamos aspecto integrador del proceso comunicativo” (Birdwhistell, 1979: 79). ¿Qué aspecto estamos obviando? La relación.

En el tono y la expresión del amigo que anuncia la llamada de teléfono puedes adivinar si se trata de una llamada no deseada o una cita. La definición de la relación, tanto si se trata de una amenaza como de una muestra de afecto, convive con la información sobre la acción: una llamada de teléfono. Una carta transmite dos mensajes: de contenido (un saludo) y de relación (“me interesas”). En el acuerdo y en el desacuerdo puede presidir la relación en ambos niveles: referencial o de contenido y relacional o conativo. Los participantes en una interacción pueden estar de acuerdo en el significado 
atribuible al contenido del mensaje y, sin embargo, discrepar en el significado relacional, en la definición de la relación. “En el peor de los casos, los participantes están en desacuerdo con respecto al nivel del contenido y también de relación.” (Watzlawick, Beavin y Jackson, 2002: 119).

El resurgir de la comunicación mediada, a finales de los noventa, tanto en el campo de la telefonía móvil como de Internet, hace cobrar nuevo valor al planteamiento de Palo Alto; sirve para evaluar los efectos que, de otra forma, pasan desapercibidos. Contemplamos cómo se reduce el espacio para los mensajes de relación, que necesitan una codificación especial en el mundo cibernético. El “emoticón” constituye una representación de tipo analógico de las emociones, al menos las emociones faciales básicas (alegría o tristeza). Éstos, junto con algunos programas de realidad virtual, buscan recrear el entorno físico y gestual en un intento de paliar las deficiencias de la comunicación informática mediada y de reducir la “frialdad” y la distancia psicológica que implica este tipo de comunicación.

Algunos programas específicos para la charla digital, como chat circles, incluyen elementos proxémicos: los participantes pueden “moverse” y relacionarse, trasformados en círculos de colores, en la pantalla del ordenador. Con ello, se busca "humanizar" las comunicaciones mediadas. A pesar de ello, la riqueza comunicativa que posee la comunicación presencial se ve mermada en parte por la mediación técnica informática. No se ha conseguido todavía aglutinar todos los componentes comunicacionales (verbales y no verbales) que intervienen y están presentes en las interacciones personales (Fanjul y Femenía, 2003). Ante esta falta de recursos no verbales la dimensión relacional ha de ser comunicada de forma explícita.

Un mensaje y, por tanto, la relación, adquiere significación en una secuencia en la que la respuesta determina si esa relación es de tipo complementario o simétrico. El significado se negocia en la interacción. El énfasis, en el área pragmática, se pone no tanto en el contenido como en la forma de la interacción, lo que lleva a identificar formas ritualizadas y reglas que las guían.

\section{2. Áreas de la comunicación no verbal}

Las investigaciones específicas en comunicación no verbal datan de fechas muy recientes, ya que realmente se comienza a profundizar en este campo a partir de 1950. Existen, sin embargo, algunos autores y obras anteriores a esta fecha que establecen conexiones entre cultura y comunicación no 
verbal (Darwin, 1872; Efron, 1941) o entre personalidad y formas del cuerpo (Kretschmer, 1925; Sheldon, 1940). Entre 1950 y 1960 se perfilan las primeras tipologías: Birdwhistell (1952) bautizará con el nombre de "Kinésica” al área que estudia los movimientos corporales y los gestos. Hall (1959) denomina "Proxémica” a la investigación sobre el uso del espacio. En 1956, Ruesch y Kees, en Nonverbal comunication: Notes on the visual perception of human relations, utilizan por vez primera el término "no verbal” en referencia a aspectos sobre el origen, uso y codificación del comportamiento humano.

A partir de 1960 aumenta de forma considerable el interés por la comunicación no verbal. Hess (1975) y Argyle y Cook (1976) inician un nuevo campo de estudio: el comportamiento y comunicación de la mirada; Roach y Eicher (1969) investigan la comunicación no verbal del vestido y los artefactos; Montagu (1971) aborda el estudio de la conducta táctil; Hall (1972) y Wiener (1966, 1967) analizan el valor comunicativo de los olores; Ekman y Friesen (1969) profundizan en el estudio de los orígenes y naturaleza de la comunicación no verbal; y Mehrabian (1971) investiga cómo interpretan los interactuantes las señales no verbales de la comunicación.

Aunque con particulares diferencias (en nomenclatura, disposición o segmentación) se puede afirmar que existe un cierto consenso general entre los investigadores en considerar como áreas de la comunicación no verbal las siguientes: la kinésica, la proxémica, los factores del entorno, la cronémica, las características físicas, los artefactos, el paralenguaje y la comunicación de los sentidos de la vista, el tacto y el olfato (conducta visual, táctil y olfativa). ${ }^{3}$

Todas estas cuestiones y áreas definidas dentro del universo de la comunicación no verbal, formarán parte activa en la construcción de la imagen corporativa de una organización. Porque la imagen no es más (ni menos) que el cúmulo de las diferentes comunicaciones emitidas por la organización en el imaginario colectivo y éstas se ven directamente influidas, complementadas y modificadas por los componentes no verbales que las acompañan. Por tanto, para construir una

\footnotetext{
${ }^{3}$ Knapp (1995) en La comunicación no verbal. El cuerpo y el entorno, realiza uno de los trabajos de sistematización más importante y serio sobre los hallazgos de los principales investigadores en el campo de la comunicación no verbal, recogiendo la mayoría de las áreas arriba referidas. Aunque este autor no considera en su obra a la cronémica, estudios posteriores han demostrado e integrado la concepción del tiempo como un campo de estudio más en la investigación de la comunicación no verbal.
} 
imagen corporativa sólida, consistente y duradera, será necesario conocer, estudiar y trabajar cada uno de estos elementos, forjando y expresando con la conjunción de todos ellos los valores, principios y filosofía que rigen el comportamiento corporativo de la organización y que, en definitiva, definen la identidad de la misma.

\section{Influencia de la comunicación no verbal en la creación de imagen}

La imagen de una empresa es la síntesis de su identidad. Por tanto, no podemos construir una sin conocer bien la otra. La imagen debe expresar los aspectos más favorables, destacables y diferenciadores que posea en esencia la organización, ya que una imagen que no esté basada en la realidad corporativa, tarde o temprano se verá descubierta y, cuando esto ocurra, la pérdida de credibilidad será más fuerte que el trabajo de imagen desarrollado hasta el momento. Existe una demanda creciente de coherencia entre lo que la empresa es y lo que pretende que creamos que es.

El conocimiento y la asunción de la realidad de una empresa son imprescindibles para lograr una imagen positiva de ella. Los consumidores y los mercados han desarrollado sutiles mecanismos de valoración de la apariencia empresarial y difícilmente hoy en día una organización puede proyectar esa imagen positiva si realmente no existe una identidad que básicamente la respalde. (Villafañe, 2002: 30)

Una vez definida la identidad de una organización, habrá que estudiar cómo proyectarla para inducir en sus públicos una imagen positiva de la misma.

La imagen es, en el mundo actual, algo muy valioso. En una sociedad eminentemente ic

Se puede decir que una imagen positiva es una de las condiciones para el éxito empresarial. Sin embargo, la imagen es algo etéreo, sobre la que se tiene un control limitado porque nace en la mente de los públicos (el protagonismo en la construcción de la imagen lo tiene el público, tanto interno como externo) y se va construyendo gracias a una multiplicidad de actos. Conocer y comprender los diferentes aspectos no verbales que intervienen en los procesos comunicativos, estudiar sus influencias y su rol en la construcción del sentido y significado final del 
mensaje, será esencial para poder controlar lo más posible la herramienta de la comunicación y dotar a la organización de una imagen que sea coherente con su historia, comportamiento y acciones (Villafañe, 2002; Álvarez y Caballero, 2004).

Bajo este prisma, cabe retomar en este punto la teoría orquestal de Palo Alto esbozada al comienzo de este artículo, ya que los principios para la construcción de imagen corporativa responden fielmente a este paradigma comunicativo. La imagen, al igual que el sentido final de la comunicación, es el resultado de la conjunción de múltiples factores que se yuxtaponen, se entrelazan y se complementan mutuamente, dando como resultado esa “pieza única”. La imagen hay que entenderla como una globalidad, como una suma de inputs o experiencias que alguien tiene con una institución. No es el resultado de una situación puntual, sino que por el contrario, se forma como fruto de la interpretación acumulativa de mensajes que llegan a los públicos. Éstos, por lo general, no se forman la imagen de una organización a partir de unos cuantos mensajes, ni tampoco se obtiene una imagen duradera con una “campaña” de imagen. La formación de ésta es un proceso lento, que implica un trabajo paciente en forma de acciones coordinadas en un programa a largo plazo (Jiménez, A. y Rodríguez, I., 2007).

Tal y como expresa Capriotti (1992), la construcción de la imagen es un proceso de simbiosis entre los diferentes tipos y matices de información, que dará origen a una acumulación positiva (suma) en caso de informaciones concordantes, o a una acumulación negativa (resta) en caso de informaciones discordantes. Este proceso acumulativo de la imagen tiene dos características básicas: es fragmentario y es diversificado. Es fragmentario porque se compone de múltiples mensajes que llegan a los públicos, los cuales son interpretados, comparados y agrupados con los anteriormente percibidos. Y es diversificado porque estos mensajes son percibidos en diversas circunstancias, diversos espacios y diversos tiempos.

Resulta interesante ver el paralelismo entre este proceso acumulativo de imagen y el concepto de “redundancia” defendida por los investigadores de la escuela de Palo Alto. Tal y como se ha expuesto anteriormente, para ellos la observación de las conductas repetidas permite conocer la lógica del sistema y así establecer un patrón general de comportamiento. En el mundo de las organizaciones, la observación reiterada por parte del público de comportamientos, acciones y otras manifestaciones corporativas coherentes y cohesionadas entre sí, les permite conocer y establecer los principios regidores de la organización y configurar así la imagen corporativa de la misma. 
La imagen de empresa no es un concepto abstracto. Es un instrumento estratégico de primer orden y un valor diferenciador y duradero. Es un "supravalor" que recubre todas las comunicaciones de la organización, identidad, personalidad y significados propios y exclusivos. Todo ello convierte a la imagen corporativa en un recurso, un activo que hay que gestionar y que bien gestionado puede generar un beneficio más importante que el beneficio económico que puedan reportar los productos o servicios con los que trabaja la empresa. La diferenciación, tan necesaria en las sociedades desarrolladas actuales, estriba ahora más en los atributos de la imagen y políticas formales de la organización, que en los propios productos o políticas funcionales de la misma (Villafañe, 2008).

Como vivimos en una sociedad hipercomunicada, las organizaciones tienen que ser cuidadosas con la imagen que transmiten. No tanto por la calidad del diseño de los grafismos corporativos, sino por la integridad de los mensajes contenidos en ellos y su correspondencia con la realidad; es decir, con su identidad y su cultura corporativa (ideologías de base y sistemas de costumbres compartidas).

De los principales intangibles estratégicos (cultura, identidad, personalidad e imagen), se puede afirmar que la imagen corporativa es la que aglutina los aspectos más relevantes de todos ellos, ya que su configuración vendrá determinada por la realidad de la organización (identidad), los valores y principios que la rigen (cultura) y las manifestaciones que efectúa voluntariamente con el fin de proyectar una imagen positiva entre sus públicos (personalidad). Realidad, valores, principios... son elementos intangibles que se manifiestan, mayoritariamente, a través de los aspectos no verbales de los elementos y las acciones comunicativas que desarrolla la entidad.

Lo primero que ha de tener en cuenta una empresa, organización o institución es que está constituida por una agrupación de personas que persiguen un objetivo colectivo y que desarrollan tareas para conseguirlo. Por tanto, la realidad de toda organización es una realidad muy humana. La empresa existe porque hay personas trabajando en ella; su fuente de energía, su motor, su dirección y su futuro depende y viene determinado por ellas (Álvarez y Caballero, 2004; Carrillo y otros, 2005).

Al igual que las personas, las organizaciones tienen personalidad. Una personalidad que se refleja en sus signos externos y también en sus formas de organización y sus relaciones internas. Resulta interesante establecer una analogía entre las personas y las organizaciones, ya que se puede 
observar como los aspectos que intervienen e influyen en la comunicación humana y que determinan la imagen personal son perfectamente extrapolables a la realidad corporativa. Las personas, para integrarse, diferenciarse y posicionarse en el maremágnum social, utilizan estrategias basadas, fundamentalmente, en aspectos no verbales. Sobre el nombre que les identifica y el cuerpo que la naturaleza les ha dado, van forjando progresivamente la imagen que desean transmitir. Se visten con ropas que determinan un estilo (de vida, de pensamiento), “adornan” su cuerpo con artefactos (anillos, colgantes, tatuajes...) que les confieren determinados valores y principios, diseñan sus espacios (casas, habitaciones) en función de sus gustos y personalidad, manifiestan su identidad a través de gestos, expresiones, comportamientos... Y la integración de todo ello a lo largo del tiempo, forja y configura su imagen personal.

Analógicamente, las organizaciones operan igual. Sobre su nombre (marca) y su cuerpo (corporate) van construyendo su imagen. Los colores corporativos, la tipografía que utilizan, el diseño de la empresa, la distribución de sus espacios, la ubicación de sus edificios, el comportamiento de sus empleados, las imágenes utilizadas en sus campañas publicitarias y un largo etcétera, van definiendo y confiriendo de forma connotada el estilo, los valores, los principios, la filosofía... que formarán parte de la imagen corporativa de la organización.

Autores como Birdwhistell y Merhabian han demostrado que los componentes no verbales de la comunicación aportan entre un 65\% y un 93\% de información y significación social sobre la verbal y afirman que, en caso de producirse contradicción entre lo que se manifiesta verbalmente y lo que se está comunicando de forma no verbal, el mensaje que prevalece es este segundo. Por tanto, si los aspectos no verbales juegan un rol de tal magnitud en la comunicación humana, no resulta descabellado pensar que la influencia de éstos en la comunicación de las organizaciones constituirá también una de sus principales piezas.

Continuando con la analogía, sería interesante comprobar la utilidad que supondría el conocimiento y dominio de las distintas áreas en comunicación no verbal y su capacidad comunicativa aplicado al campo empresarial. Actualmente, existen algunos campos de estudio que aúnan ciertos conocimientos en materia de comunicación no verbal aplicados a la comunicación corporativa y creación de imagen. La kinésica, la proxémica, los factores del entorno y los artefactos son algunos de los campos sobre los que más se ha trabajado en este sentido. 
Dentro de la kinésica ${ }^{4}$, el correcto uso de los emblemas (gestos que tienen una traducción verbal directa que es conocida por todos los miembros de un grupo o de una cultura) y la utilización fluida y coordinada de los ilustradores (actos no verbales directamente unidos al habla o que la acompañan y que sirven para ilustrar lo que se dice verbalmente), son abordados en múltiples manuales y cursos sobre técnicas para hablar en público o habilidades directivas, orientados a altos mandos o personas que, por su profesión, tratan frecuentemente con diferentes grupos. En las organizaciones, la figura del portavoz es una de las principales piezas en la construcción de imagen. Sus gestos, movimientos corporales, expresiones faciales y demás aspectos kinésicos deben ser trabajados y elaborados para transmitir la credibilidad, la seguridad y el aplomo que necesita tener la persona que "da la cara” ante el público.

La proxémica ${ }^{5}$ busca establecer los principios gnoseológicos que caracterizarían a esta especialidad de la comunicación no verbal. La concepción espacial puede influir y afectar a la capacidad para conseguir determinadas metas de comunicación. Hall (1972) sostiene que el espacio y su distribución es capaz de modificar (facilitar o dificultar) las relaciones interpersonales y de transmitir determinados valores, principios y roles. La importancia de los espacios fijos reside en que se trata del molde donde se fraguan buena parte del comportamiento de las personas. "Nosotros configuramos nuestros edificios y ellos nos configuran a nosotros”6. La arquitectura puede desempeñar un papel importante en la determinación de quién encontrará a quién y dónde. Los edificios de oficinas se construyen con frecuencia según una organización piramidal en donde los directores y grandes ejecutivos ocupan los pisos superiores y cuyos despachos son más amplios y holgados. Aquí el espacio es un símbolo de poder y status que identifica a quien lo ocupa y determina el tipo de interacción que podemos desarrollar en el mismo. La creación de un ambiente determinado a través de los factores del entorno en un espacio específico influirá en las conductas, comportamientos e interacciones de sus usuarios determinando así la capacidad sociófuga o sociópeta ${ }^{7}$ del mismo.

\footnotetext{
${ }^{4}$ Área que estudia la capacidad comunicativa de los gestos, las expresiones faciales, las posturas y los movimientos corporales.

${ }^{5}$ Área que estudia todas las relaciones espaciales como modo de comunicación.

${ }^{6}$ Palabras de Winston Churchill citadas por Hall en referencia a la influencia de los espacios de carácter fijo respecto al comportamiento de las personas.

${ }^{7}$ Por espacios sociófugos se entienden aquellos que tienen una distribución semi-fija y en los cuales se han dispuesto los factores del entorno de manera que se mantenga cierta separación entre los individuos. Por el contrario, los espacios
} 
Los factores del entorno, como medio de comunicación no verbal, son tenidos en cuenta en muchos ámbitos de nuestra vida: desde la "funcionalidad” de los edificios públicos hasta la distribución estudiada de los elementos que constituyen una oficina o una empresa para reflejar la imagen e identidad de la misma. La creación de un ambiente excesivamente formal, aumentará las probabilidades de que el comportamiento comunicativo sea más estirado, superficial y estereotipado. La distancia entre los asientos, los colores fríos (grises, oscuros), el perfecto orden de los objetos (revistas perfectamente apiladas, libros alineados), pinturas carentes de contenido, escasos objetos decorativos e incluso la extrema limpieza pueden convertir una estancia en un espacio sociófugo en el que no sabemos si sentarnos o no, si podemos coger o tocar algo y en el que la sensación de querer pasar el menor tiempo allí será creciente. Por el contrario, cuando un espacio está decorado con gusto, en tonos agradables, es luminoso, está dotado de objetos que le dan personalidad (cuadros, elementos decorativos) y posee una distribución mobiliaria adecuada para la conversación, la percepción de este entorno será cálida y psicológicamente estimulará a permanecer más tiempo en él; transmite seguridad y comodidad. Los expertos que dominan la capacidad comunicativa de los factores del entorno, trabajan sobre aspectos tales como la distribución, el color y la luz para conseguir crear ambientes que comuniquen diversas sensaciones o valores como bienestar, vanguardismo o modernidad.

En el campo de los profesionales de la comunicación, los Relaciones Públicas y Asesores de Imagen se convierten en expertos en la materia. Además de instruir y formar a las personas en sus intervenciones públicas para que sepan transmitir una determinada imagen y actitud, cuidan mucho la comunicación no verbal de los elementos que rodean tanto a estas intervenciones como a todo lo que concierne a la persona o empresa para la que trabajan (elementos decorativos, distribución de los muebles, colores del recinto, estilo). La disposición de ciertos objetos en nuestro entorno (muebles, pinturas, objetos de decoración, pantallas de televisión) contribuye a la estructura de la comunicación que tendrá lugar en ese espacio y al enriquecimiento y refuerzo de la imagen corporativa de la organización. Estos elementos pueden estar dispuestos de tal modo que reflejen ciertas relaciones de roles, que establezcan límites o bien que estimulen una mayor proximidad.

sociópetas son aquellos en los que estos factores se han dispuesto de tal forma que facilitan la comunicación e interacción. 
El color y el sonido (armónico/música o ruido) son otros de los factores del entorno que influyen en la comunicación y creación de imagen. Los colores, además de transmitir sensaciones están cargados de símbolos y significaciones que variarán según culturas. La riqueza tanto cromática como simbólica de los colores abre un amplio campo de estudio cargado de matices y significaciones. El simbolismo aislado de un color no tiene sentido si no se consideran aspectos como la tonalidad, brillo o intensidad (Deneb, 2001). La investigación ambiental sugiere que los colores, en combinación con otros factores, influyen en las conductas comunicativas de las personas y e

a la imagen de la organización. La elección y combinación de colores, así como sus connotaciones, deberán ser tenidas muy en cuenta a la hora de crear y configurar ambientes que transmitan determinadas sensaciones (austeridad, recogimiento, expansión, alegría, comodidad) que repercutirán tanto en la imagen del recinto como en las interacciones que en él se desarrollen (Knapp, 1995; Lohse y Rosen, 2001).

Finalmente, se consideran como artefactos todos aquellos elementos que utilizan las personas para modificar su cuerpo y que pueden actuar como estímulos no verbales: la ropa, el maquillaje, los postizos, las gafas y demás complementos (Davis, 1998; Hervás, 1998). El valor comunicativo de nuestro aspecto personal viene determinado tanto por nuestra apariencia física (forma del cuerpo, atractivo) como por los artefactos que utilizamos para transformarlo, que ejercen una influencia considerable sobre la forma en que nos perciben los demás y en el grado de atención que nos prestan (Wainwright, 1991; Knapp, 1995). Goffman (1963) considera el cuidado de nuestro rostro y cuerpo como un elemento comunicativo y estudia la consideración y la preocupación por la apariencia personal, las ropas que se eligen y los peinados que se adoptan. Todos estos “cuidados" tienen carácter comunicativo al poseer la capacidad de transmitir información sobre aspectos tales como personalidad, status social, profesión, identidad, valores y actitudes (Wainwright, 1991; Pérez Gauli, 2000).

La importancia del aspecto físico y el uso de artefactos en el ámbito laboral es un hecho. Muchas empresas (en especial las que tienen un trato directo con el público) son conscientes de que la imagen que transmiten sus empleados configura una parte esencial de la imagen de la propia compañía. En este sentido, cabe destacar la existencia de “manuales del empleado" o de "normas corporativas” que establecen criterios, vinculados a estas áreas de comunicación no verbal, que los empleados deben de respetar para poder trabajar en esa organización. Cuestiones como qué tipo de corte de pelo pueden llevar y qué tonalidades están permitidas, cómo deben de tener las uñas y qué colores de esmalte son los más apropiados, la exigencia de quitarse o no mostrar ante el cliente piercings y tatuajes visibles, etc., 
son aspectos que se recogen en estos manuales y que buscan establecer así una imagen cohesionada y acorde con los principios y filosofía de la empresa (Mercadona, McDonals o Disney Store son algunas de las empresas que poseen un manual del empleado que recoge este tipo de exigencias).

Para Pearson, Turner y Todd-Mancillas (1993) la comunicación artifactual, o intercambio de mensajes a través de los objetos, se refiere a la propia exhibición de elementos materiales. Ésta permite a los demás determinar aspectos tales como edad, status, rol, valores, actitudes, estilo de vida, profesión, grupos y actividades grupales en las que se participa, personalidad y género al que se pertenece. La vestimenta permite transmitir identidad, cultura y personalidad, constituyéndose así en otro de los componentes importantes para la construcción de la imagen corporativa.

La ropa es uno de los signos de identidad más definidos en la sociedad contemporánea y que ha generado mayor interés a los investigadores en comunicación; en particular, su valor como símbolo de identificación y pertenencia a un grupo social o status determinado. Los uniformes sirven para identificar profesiones o formación: una bata blanca es un símbolo que denota ciencia y tecnología y que puede llegar a identificar profesiones como investigador o médico; los uniformes y artefactos militares identifican no sólo la profesión sino el cuerpo al que se pertenece y el rango que se ocupa; los policías, mecánicos, empleados de un determinado establecimiento, deportistas o pilotos son igualmente identificados por un determinado atuendo. Los uniformes no sólo sirven para determinar la profesión; además transmiten a la persona que los porta una serie de valores y roles que influirán en la actitud, comportamiento y comunicación de los demás (autoridad ante el uniforme militar o policial, respeto ante el uniforme científico/médico o servicio ante el uniforme de los empleados de un establecimiento).

Estos son algunos d

ón no verbal que se consideran a la hora de estudiar y trabajar la imagen corporativa de una organización. La importancia para la creación de ésta no estriba en uno solo de ellos sino en la conjunción de todos y la coordinación, coherencia y cohesión de los mismos a lo largo del tiempo. Sin embargo, a pesar de su demostrado peso y contribución en la forja de la imagen, aún existen muchos aspectos, áreas, es 


\section{Conclusiones}

Las investigaciones en comunicación no verbal ofrecen a los profesionales que se dedican a la gestión de la imagen corporativa de una organización, un campo extenso y fructífero de aplicación que les permitiría aumentar la eficacia en la configuración de una imagen positiva, agradable y coherente para la misma. La comunicación no verbal constituye un lenguaje propio, lo suficientemente codificado en algunos casos, como para estudiarlo de forma sistemática y con mayor precisión. Este estudio facilitaría la comprensión de los procesos de construcción de sentido de las comunicaciones y ofrecería así un aumento del control de algunos elementos clave que intervienen en los mismos.

La imagen corporativa no es el resultado de acciones puntuales, sino que es un proceso continuo de enriquecimiento constante de los valores de base que identifican y definen a una organización. La entidad, a través de sus mensajes, acciones, manifestaciones, comportamientos y campañas, va consolidando un verdadero territorio de identidad y personalidad, que le permitirá posicionarse, diferenciarse del resto de organizaciones y que le aportará un valor duradero, con permanencia tanto en el tiempo como en la memoria social.

Resurge aquí la concepción de la comunicación como un todo, como algo global. La comunicación global (corporativa) parte de una base teórica clara que es tomada y adaptada de los axiomas metacomunicacionales definidos por los investigadores de la Escuela de Palo Alto: en una empresa todo comunica. Todo lo que la organización dice, lo que no dice, lo que hace, cómo lo hace, el contexto donde se enmarcan sus acciones, sus espacios, su apariencia y un largo etcétera, constituirán el engranaje de una “pieza única” comunicativa (su imagen). Cada expresión de comunicación debe ser pues estudiada y trabajada en todos sus aspectos (verbales, si los tiene y, fundamentalmente, no verbales), ya que constituye un elemento vital en la configuración de la imagen corporativa de la empresa.

\section{Bibliografía}

- Álvarez, T. y CABAllero, M. (2004), Vendedores de imagen. Los retos de los nuevos gabinetes de comunicación, Barcelona: Paidós. 
- ARGYLE, M. y COOK, M. (1976), Gaze and mutual gaze. Cambridge: Cambridge University Press.

- BATESON, G. [et. al.] (1994), La nueva comunicación. Barcelona: Kairós.

- BAYLON, C. y MIGNOT, X. (1996), La comunicación. Madrid: Cátedra.

- BIRDWHISTELL, R. (1952), Introduction to Kinesics. Philadelphia: University of Pennsylvania Press.

- BIRDWHISTELL, R. (1979), El lenguaje de la expresión corporal. Barcelona: Gustavo Gili.

- CAPRIOTTI, P. (1992), La imagen de empresa. Estrategia para una comunicación integrada, Barcelona: Ateneo.

- CARRILLO, M. V. [et. al.] (2005), Imagen y Comunicación en las PYMES. Madrid: Fragua.

- DARWIN, C. (1872), The Expresión of Emotions in Animals and Man. Versión del castellano en DARWIN, C. (1984), La expresión de las emociones en los animales y en el hombre. Madrid: Alianza.

- DAVIS, F. (1998), La comunicación no verbal. Madrid: Alianza.

- DENEB, L. (2001), Diccionario de símbolos. Madrid: Biblioteca Nueva.

- EFRÓN, D. (1941), Gesture and environment. Nueva York: King’s Crown Press.

- EKMAN, P. y FRIESEN, W. V. (1969), “The repertoire of nonverbal behavior: categories, origins, usage and coding” en Semiótica, 1: 62-98.

- FANJUL, C. y FEMENÍA, S. (2003), Una nueva cultura docente. Los retos de la educación on-line. Valencia: UCH-CEU.

- GOFFMAN, E. (1963), Behavior in Public Places. Nueva York: Free Press.

- HALL, E. T. (1959), The Silent Language. Nueva York: Doubleday.

- HALL, E. T. (1972), La dimensión oculta. México: Siglo XXI.

- HERVÁS, G. (1998), Como dominar la comunicación verbal y no verbal. Madrid: Playor.

- HESS, E. H. (1975), “The role of pupil size in communication” en Scientific American, 233: 110112, 116-119.

- JIMÉNEZ, A. y RODRÍGUEZ, I. (2007), Comunicación e imagen corporativa. Barcelona: UOC.

- KNAPP, M. L. (1995), La comunicación no verbal. El cuerpo y el entorno. Barcelona: Paidós.

- $\quad$ KRETSCHMER, E. (1925). Psyche and character. New York: Harcourt Brace.

- LOHSE, G. L. y ROSEN, D. L. (2001), "Signaling quality and credibility in yellow pages advertising: the influence of color and graphics on choice” en Journal of advertising, 30(2): 73-85.

- MARTÍN SERRANO, M. (1982), Teoría de la comunicación I. Madrid: Alberto Corazón editor. 
- MATTElART, A. y MATTElART, M. (1997), Historia de las teorías de la comunicación. Barcelona: Paidós.

- MEHRABIAN, A. (1971), Silent Messages. Belmont: Wadsworth.

- MONTAGU, A. (1971), Touching. The Human Significance of the Skin. Nueva York: Columbia University Press. Harper \& Row.

- MORRIS, C. W. (1958), Fundamentos de la teoría de los signos. México: Universidad Nacional de México. También se puede consultar el artículo original en MORRIS, C. W. (1938), Foundations of the theory of signs en International Encyclopedia of Unified Science, 1(2). Chicago: University of Chicago Press.

- PEARSON, J. C., TURNER, L. H. y TODD-MANCILLAS, W. (1993), Comunicación y género. Barcelona: Paidós.

- PÉREZ GAULI, J. C. (2000), El cuerpo en venta. Madrid: Cátedra.

- RAMÍREZ, T. (1995), Gabinetes de comunicación, Barcelona: Bosch.

- $\quad$ ROACH, M. E. y EICHER, J. B., (1965), Dress, adornment and the social order. Nueva York: John Wiley \& Sons.

- $\quad$ ROSENGREN, K. E. (2000), Communication. An Introduction. London: Sage.

- RUESCH, J. y KEES, W. (1956), Nonverbal Communication: Notes on the visual perception of human relations. California: University of California Press.

- SCHEFLEN, A. E. (1973), Communicational Structure: Analysis of Psychotherapy Transaction. Bloomington: Indiana University Press. Referencia tomada de BATESON, G. [et. al.] (1994), La nueva comunicación. Barcelona: Cairos, p. 24.

- SHELDON, W. H. (1940), The varieties of human physique. Nueva Cork: Harper \& Row.

- VALBUENA DE LA FUENTE, F. (1997), Teoría General de la Información. Madrid: Noesis.

- VILlAFAÑE, J. (2002), Imagen positiva. Gestión estratégica de la imagen de las empresas, Madrid: Pirámide.

- VILLAFAÑE, J. (2008), La gestión profesional de la imagen corporativa, Madrid: Pirámide.

- $\quad$ WAINWRIGHT, G. R. (1991), El lenguaje del cuerpo. Madrid: Pirámide.

- $\quad$ WATZLAWICK, P., BEAVIN, J. y JACKSON, D. (2002), Teoría de la Comunicación Humana. Barcelona: Herder.

- WIENER, H., (1966, 1967) “External Chemical Messengers” (I, II, III) en New York State Journal of Medicine, vol. 66(24): 3153-3170; vol. 67(9): 1144-1165; vol. 67(10): 1287-1310. 